\title{
Lean Management Based Sustainable Transport System for Surat Metropolitan Area in the Context of Industrial Development
}

\author{
Suresh Sharma ${ }^{1}$, Pankaj J. Gandhi ${ }^{2,3}$ and Anil Kumar Roy ${ }^{3}$ \\ 1. Doctoral student, Faculty of Business and Management, Himalayan University, Surat 395009, India; \\ 2. Ph.D. Guide, Visiting Faculty at Veer Narmad South Gujarat University, Surat 395009, India; \\ 3. Faculty of Planning, CEPT University, Ahmedabad 380009, India
}

\begin{abstract}
Surat city is continuously expanding with industrial development. Despite several flyovers, traffic congestion continues in the heart of city. Therefore, fresh transportation planning is at anvil. Simultaneously, further expansion plan is under consideration to create yet another, the 10th industrial zone. Purpose of this paper is to explore lean management based sustainable transport system for meeting the increasing needs of people and supply-chain. The research examines different mode of transportation like; vehicles on road, rail on the land, and steamers through the sea route to provide connectivity. This study may support the planners of the smart city. The study intends to find how lean management can be integrated to sustainable transport system meeting objectives of lean and sustainability both. Lean management system claims to be capable of eliminating all type of wastes including those associated with transport system. On the other hand, sustainable transport claims to meet the needs of people in personal economic lives, importantly respecting the need of future generations. Therefore, this applied research aims to find a lean and sustainable transport solution. This research work can be seen as descriptive type as it includes survey of location and fact finding enquiries.
\end{abstract}

Key words: Lean management, sustainable development, environment health and safety, people-planet-profit.

\section{Introduction}

Surat is located on the southern part of Gujarat approximately between $21^{\circ}$ northern latitude and $73^{\circ}$ eastern longitude as cited in Fig. 1. Creation of a mega cluster is in view at Pinjarat, using non agricultural zone in Olpad Taluka. Fig. 2 illustrates locations of different areas in Surat. Shifting of many old units together with new ones will reduce transport congestion. Single track rail line already runs up to heavy industries in the vicinity. The aim is to find possibilities of connecting the new industrial area with other locations in east, north and south. Surat faces Arabian sea in the west nearly at 10 kilometers from the proposed industrial area. At present, there are nine developed industrial estates. The district is mainly

Corresponding author: Suresh Sharma, doctoral student; research fields: lean management and total quality Management. E-mail: suresh_sharmas@rediffmail.com. known for textiles and diamond processing industries. It is gradually emerging as a potential hub for IT sector in Gujarat. Hazira and Magdalla ports in Surat provide logistic support to the industrial operations both for heavy engineering and MSME (micro, small, and medium enterprise) sectors.

As regards minerals, Surat is the second largest producer of lignite in Gujarat with about $20 \%$ of total production in the state. There are lignite based thermal power stations producing and transmitting electric power. Some of the material based industries on medium and large scale in the district produce; stone ware, drainage pipe, and glass wares. Existing status of industrial estates in Surat district is illustrated in Table 1, based on synthetic data [1]. Figures in the table are only indicative and require to be updated. In fact, all inclusive number of industrial units registered from 1984 to 2011 figured as 68,312. Published data 
and information highlight the progressive industrial scenario of Surat. About $65 \%$ of the total diamond exports from India is from Surat alone. Surat is also synthetic capital of India having more than 65,000 power looms, 500 crimping and 400 processing houses. This sector provides about one million jobs. Large and medium companies located in Hazira include; Bharat
Petroleum Corporation, Essar, Hindustan Petroleum, Larsen \& Toubro, Reliance, ONGC, NTPC, KRIBHCO and many others. Shell has an LNG (liquefied natural gas) terminal at Hazira for regular bulk supply. Pharmaceutical, chemical, and petrochemical products are the most export oriented goods of Surat.

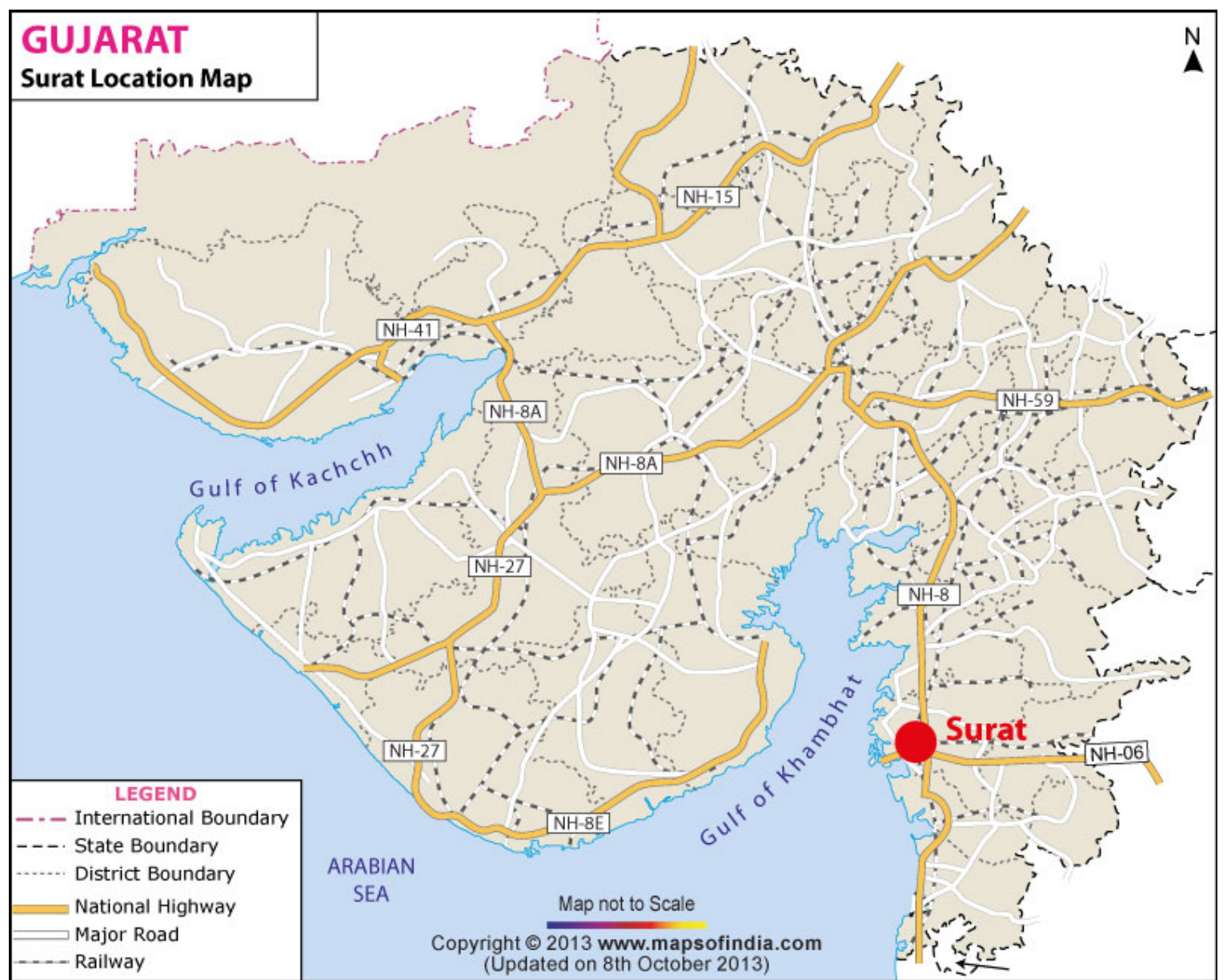

Fig. 1 Surat location map.

Table 1 Status of industrial estates in Surat.

\begin{tabular}{llr}
\hline Location No. & Name of industrial area & Land acquired and developed (Hector) \\
\hline 1 & Sachin & 749.35 \\
2 & Pandesara & 218.27 \\
3 & Surat Apparel Park & 54.96 \\
4 & Bardoli & 4.71 \\
5 & Ichhapore-Bhatpore -Kawas & 919.84 \\
6 & Hazira-Mora & 428.04 \\
7 & Khatodara & 3.08 \\
8 & Olpad & 31.59 \\
9 & Katargam & 38.33 \\
\hline
\end{tabular}

Source: GIDC (Gujarat Industrial Development Corporation), Surat. 


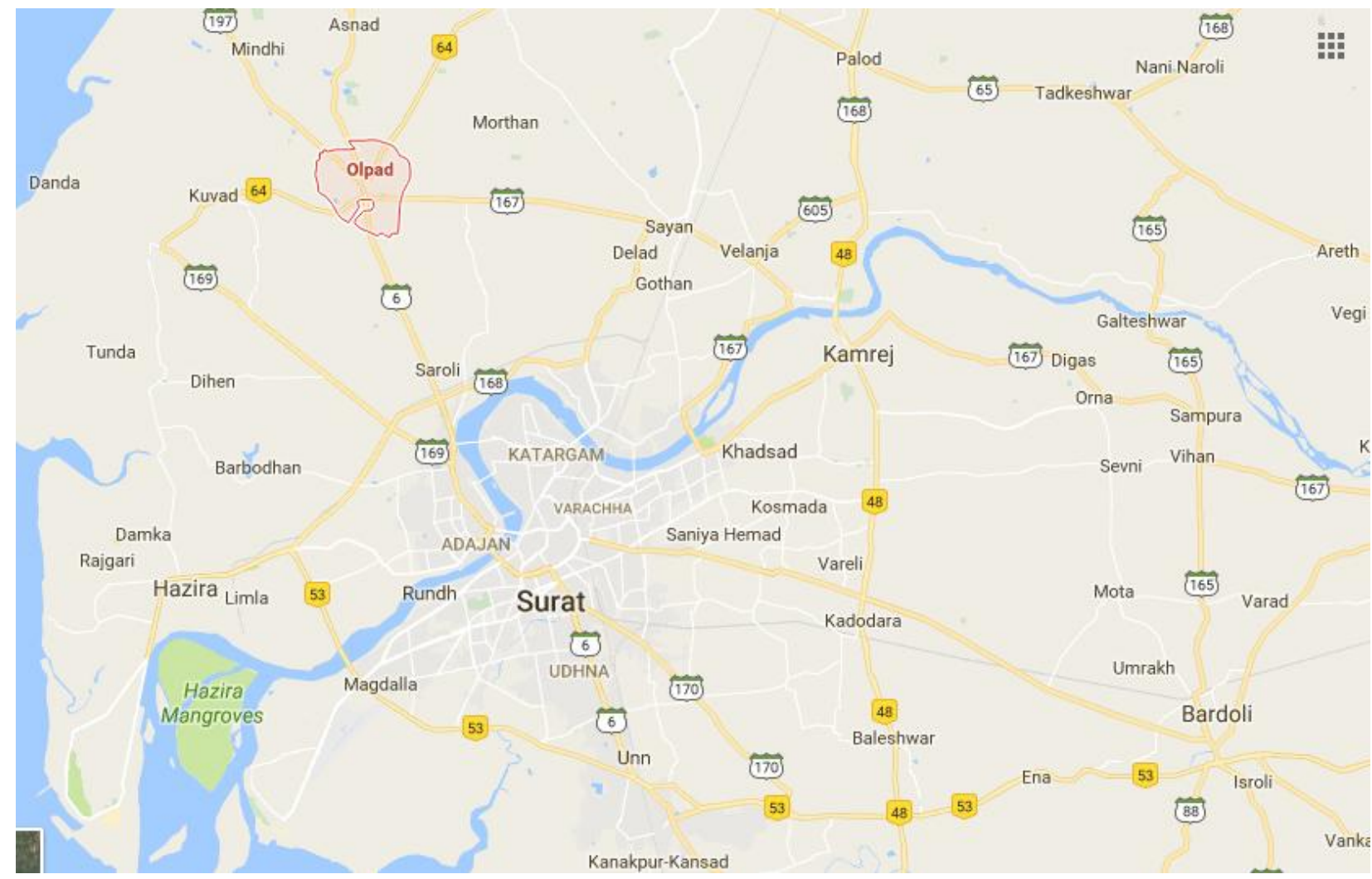

Fig. 2 Village Tena and Pinjarat at extreme west, between Olpad-Hazira.

Linkage and connectivity to (National Highway) NH-6 and NH-8 by road is satisfactory but Surat-Hazira Rail link together with road transportation infrastructure requires further augmentation to support the proposed expansion plan. Surat domestic airport is connected to different metros. It has daily flight to Delhi, Jaipur, Ahmedabad, Mumbai and Kolkata. The state government has undertaken an aviation plan for up gradation of Surat airport.

The current paper reports proposal by the Authors for consideration of decision makers at the state and central government levels. It is area specific research work prior to executing expansion plan of developing industrial corridor along Tena and Pinjarat villages.

An integrated approach has been applied to combine lean and sustainable transport. It attempts to include short and long term, intra and intercity, urban and rural, passenger and freight transport of all models. It also contains reflection and interest of local population considering the objective of sustainable development to eradicate poverty of local inhabitants. In the course of search and survey, many queries and questions stemmed. One statement of cultivator community (Khedut Samaj) speaks volume, “A bridge on the creek near village Tena has been recently inaugurated. The people of the village thought that the bridge was being built for them, to cut the travel time from their village to city. Now with the plan of relocation of the industrial units out in the open, they have realized that the plan was not really for them, while it may help them. It was actually to motivate the industries to relocate to the new area" [2]. Authors therefore, attempt to find answers to support the sustainable development in the specified area and at the same time, invite attention of policy makers to a recommendation of United Nations Secretary-General's Advisory Group in the book titled Mobilizing Sustainable Transport for Development. It states, "Well-intentioned policies formulated at the state level may not be properly implemented at the local level if they are not made coherent with local 
priorities" [3]. The aim of the research is also to focus on such areas where the town planners with their expertise can add real value - in policy, in financing, and in technology lest it is misunderstood as land grab.

\section{Literature Review}

The literature review here comprises of three sections; transportation as service, lean transportation, and sustainable transport. Published papers on the above topics have been critically reviewed duly guided by the research objective of integrating them together. Attempts have been made to relate current study with the previous studies and to conclude by summarizing what the literature suggests.

\subsection{Transportation as Service}

Transportation is a major component that promotes trade. Movements of goods and people provide economic wealth and power to states as well as to industries. It facilitates production and consumption of goods to occur in different locations. This section delivers an overview of transportation modes that are of interest in the context of industrial development in Surat. Other relevant aspects like transportation concepts and transportation planning are also included. Transportation is regarded as a service [4]. Demand versus capacity of transportation needs to be synchronized because unused transportation capacity of one period cannot be stored for use in future period. Therefore, transportation planning assumes one of the important roles. Subsequently, it is termed as transportation management when three aspects are integrated in the scope; transportation, supply chain, and logistics. Thereby, transportation management is understood to include the tasks of planning, control, and execution. As defined by Chopra and Meindl, transportation refers to the movement of objects from one location to another, beginning with raw material supply to industry and ending with finished product delivery to customers or consumers [5]. Fleischmann extends it further and states the transportation to be the means of bridging the dimensions for objects. These so-called objectives may be people, information, or physical products [6]. Simons and associates argue that avoidable transportation could be classified as waste. But efficient transportation through right planning and execution is value adding stream. Efficient transportation is therefore important at an economic, social and environmental level as well as for company's profitability. The choice of the right type of transportation service is the key decision with regard to transportation planning and network design [7]. The most commonly used transportation mode for covering local and regional distances in the present context of expansion plan is the road. For heavy loads from longer distances could be rail transportation in the region. Overseas supply in large volume can be transported by ship and steamers to the identified area at an advance stage. However, transportation management needs to find viability considering the demand versus capacity. Objective is to decrease congestion and increase safety in the Surat metropolitan area. Therefore, the attempt is to find out the best form of models that can appropriately explain and predict the relationship between traffic flow, density, and speed. Traditionally, traffic volumes are determined by carrying continuous traffic counts over a period of one or more years using permanent ATRs (automatic traffic recorders) [8].

Outflow of traffic has been equated as:

$$
\text { Flow }=\text { density } \times \text { speed }
$$

where, speed is specified in $\mathrm{km}$ per hour, flow in number of vehicles per hour, and density in number of vehicles per km [9].

Since it is impractical and expensive to install ATRs on all roads, readily available data sources are recommended to use for estimating traffic volume on the new rural roads in the specified area.

\subsection{Lean Transportation}

Transportation system of the present time has the challenging task to provide safe, quick, economic, and convenient movement of persons and goods. Therefore, 
multiple disciplines of transport are required to be managed scientifically. This study examines the benefits of lean management in transportation industry. Although this concept has not been used adequately in the transportation sector, interest is growing fast all over. Transportation can benefit from lean management as posted by Robert Martichenko (2014), citing the lean philosophy, he further argues; waste always exists, and no matter how good the current process is, it can always be improved [10]. Lean management claims to have provided enhanced efficiency to organizations in smooth flow of materials and reducing waste throughout the process. The claim includes highway construction and supply chain as well. How transportation management professionals will implement lean is the subject of the study. Professionals in this field however, agree with the fact that significant waste and unnecessary costs do exist in most transportation network. Therefore, lean management has the immediate application to improve such situation. Lean management is based on improving efficiency by removing wasteful steps that do not add value to the final product or service. It provides better and more efficient ways of accomplishing the same tasks. It also helps to cut cost and deliver what the customer wants and is willing to pay for [11]. Lean management works on continuous improvement philosophy applying effective tools like KAIZEN. In simple term, waste is identified, analyzed to find root cause, and the cause of waste is eliminated. The cycle is repeated continuously. JIT (just-in-time) tool of lean management is focused on getting the right things to the right place at the right time in the right quantity eliminating every type of waste [12]. Transportation and logistics professionals may find such a tool naturally applicable and beneficial to their business. In fact, other discipline within the organization like highway construction has already derived benefit applying lean management. Robert, CEO of LeanCor advocates that in order to create operational and financial stability, firms will have to manage their transportation process using lean principles. Focus is put on total costs associated with logistics including purchasing, transportation, warehousing, ordering, and inventory carrying costs.

Robert Martichenko finally recommends five guiding principles of lean transportation management as under:

- Develop and execute transportation strategy with the customer expectations and meet these expectations with optimal inventory levels based on lean inventory strategies;

- Eliminate transportation waste such as found in the form of excess and unnecessary transportation miles compared to actual requirement;

- Measure transportation performance based on service provided to build long-term relationship with quality carriers that are stable, dependable, and committed to serve the organization;

- Understand transport cost structure in two parts; unit costs and productivity costs. Productivity costs can be continuously reduced by; optimizing trailer's utilization, total miles running, equipment waiting-time-reduction which is pure waste, and adherence to carrier route. Unit costs or carrier rates need to be negotiated such that they are fair, competitive, and equal for all parties. There has to be win-win situation for both the parties;

- Perform transportation daily event management as recommended below.

(1) Achieve cost savings from systematic, daily event management and hour-to-hour focus on waste identification and their reduction;

(2) Start with transportation plan every day, execute the plan, and then check actual status;

(3) Create daily route design, complete real time tracking, generate real time metrics, and accomplish daily problem solving task.

J. Trent propagates "pull" philosophy of lean management in the context of lean transportation recommending a shift from "push" logic to "pull" strategy. Therefore, he criticizes the push logic that 
tries to minimize transportation cost by minimizing the number of travelled miles, minimizing the number of empty miles and maximizing capacity-full use of materials by transporting large lot sizes. On the other hand, he opines that pull strategy supports the idea of work flow through the supply chain by providing predictable, more frequent and smaller quantities at a specific point of use [13].

Big automobile manufacturers like Toyota and others responded quickly by shifting from "push" to "pull" and achieved great success. They implemented in steps, firstly shifting from mass production to batch production system. Finally, they shifted from batch production to one-piece-flow cell based on "pull" philosophy [12]. Transportation professionals may face practical problems while implementing pull strategy but survival and continuous growth is the motivating awards. The best way to handle the challenge of pull strategy, as recommended by James P. Womack, is to coordinate with real customer to know exact requirement and to work backwards to supply as desired [11].

\subsection{Sustainable Development and Sustainable Transport}

In this section, attempt is made to review relevant published papers on the sustainable transportation. Analysis of critical discussions, differing arguments, theories and approaches have been made with reference to the selected topic of the lean management based sustainable transport system for Surat metropolitan area in the context of industrial development. Area of controversy has raised questions that have been partially answered, leaving some for further research work.

\subsubsection{Sustainable Development}

Sustainable development is defined by commission of the United Nation as "development that meets the needs of the present without compromising the ability of future generation to meet their own needs" [3]. The development emphasizes on balancing local and global efforts to meet basic human needs without destroying or degrading the natural environment. Relationship between these needs and the environment is represented by the help of Venn diagram shown in Fig. 3.

Goals were identified as economic development, social development and environmental protection. This theory has been expressed using three overlapping circles representing three pillars of sustainability. It is illustrated that both economy and society are constrained by environmental limit. Therefore, sustainability is something that improves the quality of human life, while living within the carrying capacity of supporting eco-system [14]. There is yet, different school of thought as advanced by Tuskington where sustainable debate has moved on from ecological and environmental to the social and economic areas, such that social sustainability has emerged as theme in its own right [15]. This is not to suggest that these two dimensions are completely independent of one another. They are two faces of the same coin.

\subsubsection{Sustainable Transport}

Contributing literature on sustainable transport: the high-level advisory group of United Nation has advanced a definition, "sustainable transport is the provision of services and infrastructure for the mobility of people and goods - advancing economic and social development to benefit today's and future generation-in a manner that is safe, affordable, accessible, efficient, and resilient while minimizing carbon and other emissions and environmental impacts" [3]. It further propagates that sustainable transport would only be achieved in close coordination with important stake holders like; transport industry, research institute, local and central government and area based public organizations. Such a team is formed and engaged to work proactively for real progress. Sustainable transport will result only with such a joint venture. Sustainable transport supports people to access what they need such as jobs, markets, goods, social interaction, education and many other services 


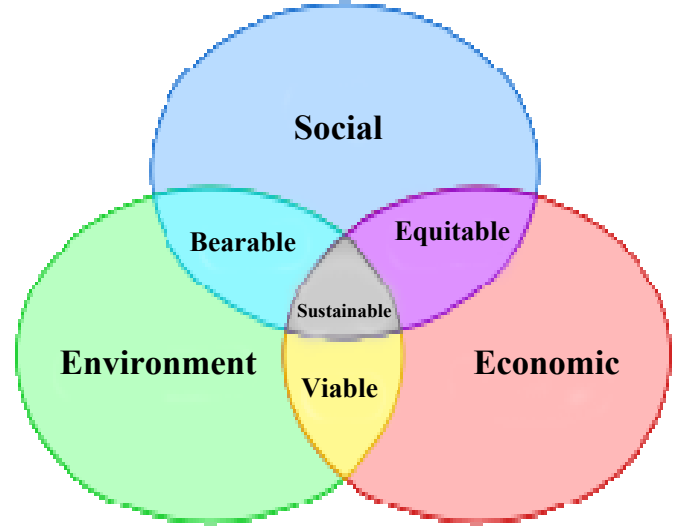

Fig. 3 Sustainability diagram.

contributing to healthy and satisfied lives. It empowers women and persons with disabilities. Sustainable transport on the other hand, essentially puts effort to; fight climate change, reduce air pollution and improve road safety. It is expected to help the Surat metropolitan area in reducing congestion and pollution.

Before finding further as to what all it can deliver, it is pertinent to discuss what can be immediately done with the existing traditional approach of passenger and freight transport. An alternative concept known as "avoid-shift-improve" is built on the principles of sustainability as found below:

- Avoiding: inefficient or unnecessary travel or transport, where appropriate means are available through city planning like public transportation management, e-communication, etc;

- Shifting: travel plan or transport to improve trip efficiency by ideal mode like shifting to off-peak travel;

- Improving: transport vehicle performance. This can be done using better technology, operation and infrastructure thereby making them more energy efficient and less carbon intensive. Transport is responsible for $23 \%$ of global energy related greenhouse gas emissions as per data from International Energy Agency, 2015.

- United Nation promotes following concepts under the sustainable development frame work:

- Sustainable development goals: no poverty, zero hunger, good health and well-being, quality education, gender equality, clean water and sanitation, affordable and clean energy, reduced inequalities, climate action, decent work and economic growth, safe life below water, healthy life on land, Industry-innovation and infrastructure, sustainability cities and community, responsible consumption and production, peace-justice and strong institutions, partnership for the goals;

- The 5 Ps for current and future generations: people, planet, prosperity, peace, partnership;

- The 5 Is of sustainable transport-areas of action: infrastructure - enabling services; innovation-for the future; integration - of the modes; intelligence - capacity building and training; investment - to create a virtuous cycle;

- The 5 Cs of sustainable transport-to meet the needs of clients: client - meeting expectations with quality services; centers - passenger and logistic hubs corridors-connecting the hubs; congestion-low pollution with improved efficiency; complementary — optimized transport systems;

- Enabling: enabling is added to the framework and therefore innovative technologies are integrated into sustainable transport drive to achieve desired results.

\subsubsection{Examples}

Autonomous vehicles are example of enabled technology. Development of alternate fuels like; bio-fuel for aviation, CNG (compressed natural gas) and LPG (liquefied natural gas) for heavy trucks will support sustainable transport goal. Electrification of vehicle for short distance transport such as passenger cars, buses, light rail, and waterborne transport is setting good trend. Other initiatives like use of electric two-wheelers in cities and tax incentive on hybrid and electric vehicles are good examples of enabling. Hybrid bus technology saves fuel consumption of $30 \%-40 \%$. Rail with well developed smart grid technology [16] is an example of enabling sustainability. Road connectivity and integration of ICT (Information and Communication Technologies) 
into vehicle help in reducing congestion, travel time, and allow real time change of rout.

\section{Methodology Adopted}

Research methodology as a system helped in designing the research process for the current topic. Methodology also supported in determining the appropriate research methods. Qualitative research methodology was selected and used starting from designing the research questions to developing the protocol and finally selecting the sampling methods. Facts and figures on lean-transportation, transportation-industry, sustainable developments, and ground realities of Surat metropolitan area have been collected and analyzed. Qualitative methodology was adopted to understand people's belief, perspective and experience. This methodology supported the researcher also in handling the important issues of consent and confidentiality. Information and data were collected through individual interview method. In-depth qualitative interviews were conducted with open ended questions to gain maximum information. Local residents were respondent in individual capacity. On different occasions respondents expressed their current view on issues of transportation in locality. Community leader shared own fear of land acquisition, whereas others expressed hope for the opportunities the industrial corridor might bring to the Pinjarat, Tena and other villages in the vicinity. As regards sampling, convenience sampling method was adopted to save time, money and effort. However, credibility was maximized by selecting right and elected representative. Some written and published reports were included in the research work in the form of context related synthetic data. Such written sources include; reports of previous research work in the field, policy reports from authentic agencies, and opinion posted by stakeholders on internet. The other methods adopted by researchers were direct observations to record pattern and timing of transport congestion in the city. Survey of the proposed site allocated under expansion plan was also carried out as a fact finding method.

\subsection{Proceedings}

In this section, the researchers attempt to record the collected data, information, observations, survey reports, and relevant evidence to support the research work carried out on "lean management" based sustainable transport system for Surat metropolitan area in the context of industrial development. At this stage, the researchers like to be in the role of recorder only restricting comments. However, outcome of the research work appears in the next concluding Section 4, based on the analyzed valid data, supporting evidence, and literature review.

\subsubsection{Traffic Congestion}

The issue related to traffic congestion has been discussed in Section 2.1. Previous research paper has been placed under reference that provides effective models for estimating traffic parameters using readily available data sources.

The picture placed in Fig. 4 above illustrates the traffic congestion situation on all working days between 11:00 a.m. to 8:00 p.m. in the textile market area of Surat despite joint efforts of municipality corporation and traffic police on hour to hour basis. Local newspaper Divya Bhaskar, (2017c) dated Jan. 9, 2017, Page No. 2, reported about a decision to close for two hours frequently the textile market road seen in Fig. 4 above for all power operated vehicles.

Development of sustainable transport system in Surat metropolitan is planned to find answer to the traffic congestion.

3.1.2 News Paper Report-Mega Cluster in Pinjarat Local newspaper Divya Bhaskar, (2017b) dated Jan. 6, 2017, Page No. 5, reported about new investment plan in year 2017 for a mega cluster project in Pinjarat village. This news attracted interest for a detailed study. Estimated investment in real estate is indicated as INR 2,000 crore. Different units are expected to invest about INR 10,000 crore. Villagers in the locality may get 


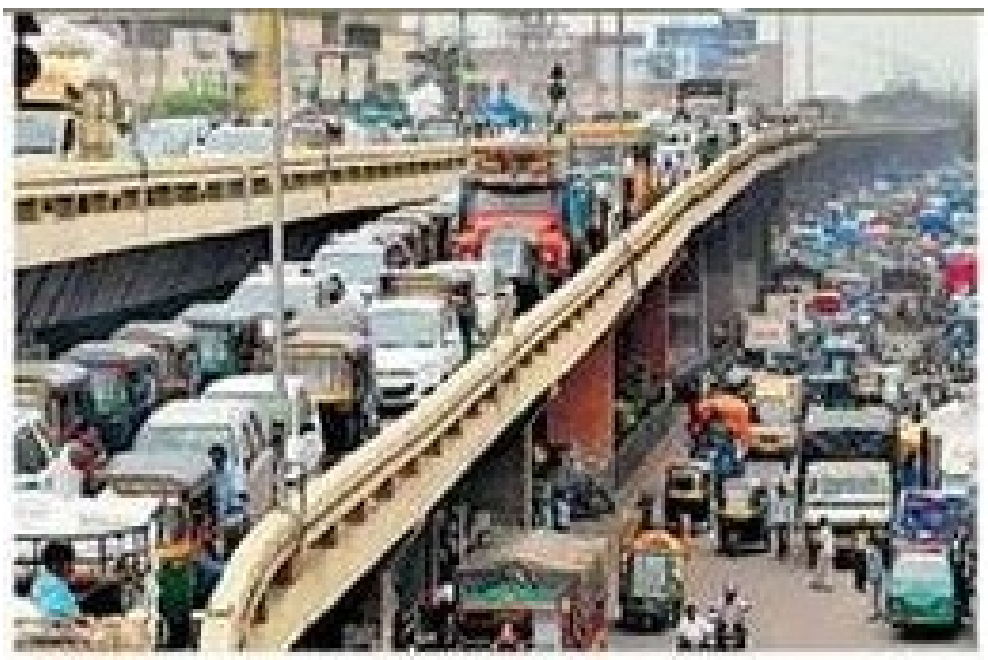

Fig. 4 Traffic congestion during peak hours.

opportunity of employment, small scale business, and sustainable transport system to improve quality of life.

\subsubsection{Surat Urban Development Plan 2035}

Internet source provides information on Surat Urban Development Plan 2035 [2]. On December 9, 2015, 104 villages of five talukas, namely Olpad, Choryasi, Kamrej, Pasana, Mangrol of Surat district were included in SUDA (Surat Urban Development Authority). In a press conference on May 7, 2016, a Development Plan (DP)-2035 was announced and notification for the same was published on May 10, 2016. DP-2035 claims that the population of Surat would touch 1.10 crore in 2035. The proposed expansion is nearly three times the present area which accommodates a population of 55 lakhs. Hence, the expansion is felt justified. The blog on the internet posted by secretary of cultivator community questioned whether the people of the villages likely to be affected by the proposed expansion were ever consulted. Based on the study of plans, maps and land use calculations, it was found and reported that the DP-2035 had proposed an industrial corridor along Tena-Pinjarat outer road on both the sides west as well as east.

3.1.4 Respondent's View

In-depth qualitative individual interviews brought out diversified views with local life histories narrating changes encountered in the past and envisaged in the context of transportation and industrial corridor project. About 54\% of the respondent expressed hope from the project to get better transport support, easy access to market, job creation, and well-being of less privileged persons. Others expressed fear of getting shifted to smaller new undeveloped plots losing their livelihood, cattle, and cultivation. This section of respondent raised question about the town planning move whether it is farm-friendly. They only hope that expansion will take place at western side of outer road along Tena-Pijarat village towards sea-sore, as done at Hazira belt a decade before.

3.1.5 Visionary Agenda for Sustainable Transport

Transport is a service provider using its infrastructure for mobility of people and goods. The modern world requires it to provide safe, expedient, economic and convenient movement. Today it is possible to move an object from earth to moon in 8 hours 35 minutes [17]. It is impossible to move the same object so safely at a much lower speed on earth without causing congestion and pollution. Transport is responsible for $23 \%$ of global $\mathrm{CO}_{2}$ emissions. Therefore, there is significant scope of improvement in the transportation service. In the past, professionals in this field had to resort to personal experience, judgment 
and luck. Driver behavior played important role earlier in governing. Now there is visionary agenda to transform this service into sustainable transport true to its definition. United Nation advisory group advocates and recommends solution through behavioral and physical sciences for mobilizing sustainable transport for development [3].

\section{Conclusions}

The study on lean management based sustainable transport system for Surat metropolitan area in the context of industrial development presents real time situation, sustainable developments, recommendations, action plans, and views of people at different strata of society. It attempts to integrate two popular concepts of lean and sustainability to a vital industry engaged in improving quality of life through transportation service. Briefly, it has addressed existing best practices in sustainable transport industry. The study is for consideration of professionals engaged in the field, town-planners and decision makers for value addition.

\section{Acknowledgments}

The authors acknowledge and thank all those who supported throughout the study and interviews including valuable editorial review comments and suggestions which greatly improved the paper.

\section{References}

[1] MSME-Development Institute, Government of India. 2011. Brief Industrial Profile of Surat District. Accessed February 1, 2017. http:www.msmediahmedabad.gov.in.

[2] Surat Urban Development Autority (SUDA). 2016. Surat Urban Development Plan-2035. Accessed June 25, 2016. https://counterview.org.

[3] Ki-Moon, B. 2016. Mobilizing Sustainable Transport for Development. United Nation Official Publication.
[4] Millen, R. S. 1999. "Quality Management in Logistic Function: An Empirical Study.” The International Journal of Quality \& Reliability Management 16 (2): 166-80.

[5] Seiler, T. 2012. Operative Transportation Planning: Solutions in Consumer Goods Supply Chains. Heidelberg: Physica-Verlag.

[6] Fleischmann, B. 2011. "Transportation Services in the Consumer Goods Industry." In Operative Transportation Planning, edited by Thorben Seiler. Heidelberg: Physica-Verlag.

[7] Simon, et al. 2004. "Transportation Services in the Consumer Goods Industry." In Operative Transportation Planning, edited by Seiler, T. Heidelberg: Physica-Verlag.

[8] Aunet, B. 2000. "Wisconnsin's Approach to Variation in Traffic Data." Prestented at North American Travel Monitoring Exhibition and Conference (NATMEC), Middleton, Wisconsin.

[9] Mustapha, H. N. 2016. "Outflow of Traffic from the National Capital-Flow Speed and Density Relationships." Journal of Traffic and Transportation Engineering (English Edition) 3 (6): 540-8.

[10] Martichenko, R. 2014. "Guiding Principles of Lean Transportation Management.” Accessed March 4, 2017. http://www.rgllogistics.com/blog/topic/transportation.

[11] Womack, J. P., and Jones, D. T. 2003. Lean Thinking. New York: Simon \& Schuster.

[12] Liker, J. K. 2004. The Toyota Way. New York: Tata McGRAW-HILL.

[13] Trent, R. J. 2008. End-to-End Lean Management: A Guide to Complete Supply Chain Improvement. Fort Lauderdale: J. Ross Publishing.

[14] Wikipedia. n.d. "Sustainability: Global Human Impact on Biodiversity." Accessed February 1, 2017. https://en.wikipedia.org/wiki/Sustainability.

[15] Turkington, R., and Sangster, K. 2006. "From Housing to Social Mix: Housing's Contribution to Social Sustainability." Town and Country Planning 75: 184-5. Accessed February 1, 2017. http://www.interscience.wiley.com.

[16] Merlin. n.d. "European Union Research Project Merlin (2012-2015) on Energy Management for Railway Systems." Accessed February 1, 2017. http:www.merlin-rail.eu.

[17] O' Neil, I. 2008. "How Long Does it Take to get to the Moon?." Accessed February 1, 2017. http://www.universeday.com/13562/how-long-does-it-tak e-to-go-to-the-moon. 